\title{
Barriers inhibiting the transition to sustainability within the Australian construction industry: An investigation of technical and social interactions
}

\begin{abstract}
Research concedes that the building industry in Australia has fallen short of satisfying sustainability requirements. Currently, the responsibility for transitioning the building industry into one that is sustainable is laid largely at the feet of low-carbon governance instruments such as mandatory codes and sustainability rating tools. The behavior of groups, interactions of individual actors, relationship between actors' and group level behaviors that affect implementation of these instruments have, however, received only cursory attention. This study therefore seeks to move beyond the instruments debate and identify a broader range of factors inhibiting the transition to sustainability within the Australian building industry. It draws on focus group discussions held with 26 leading sustainability experts and practitioners from around the country. Whereas, earlier work on impediments to sustainability pre-identify potential causal factors, this study, with Sustainability Transition as the theoretical lens, allowing for new and as yet unidentified impediments to emerge. Indeed, while findings confirm a range of technical shortcomings hindering sustainability transition, the deeper barrier is shown to be the prevalence of a dysfunctional sustainability ecosystem where siloed vested interest groups exploit Australia's ineffective transition regimes for their own gain. The practical implication is that current efforts to refine rating tools and modify building practices - remedies identified in earlier research - will not be enough to effect meaningful transition, as long as end-users remain disenfranchised, confused and unpersuaded of the benefits of sustainable buildings.
\end{abstract}

Keywords: Sustainability transition; green rating tools; green buildings; low carbon; social dynamics; sustainable construction 


\section{Introduction}

The construction, operation and maintenance of buildings in Australia account for around $25 \%$ of the nation's annual carbon emissions (van der Heijden, 2018). As Australia's population continues to grow, there will be a need for even more buildings. In 2017, around 18,000 dwelling units were approved for construction monthly (ABS, 2018). Melbourne will need another 720,000 homes by 2031 (Masanauskas, 2014); Sydney, another 664,000 new homes within 20 years (Foong et al., 2017). The number of residential units across Australia will reach 10 million by 2020, compared to just 6 million in 1990 (Saman, 2013). Against this backdrop, the sustainability phenomenon has taken on increased importance in recent years, and accordingly the demand for more sustainable buildings is on the rise (Martinaitis et al., 2015, Darko et al., 2017). Compounding this demand, the building industry is required to adopt practices and processes that produce buildings sustainably (Berardi, 2012). By definition, sustainable buildings are expected to minimize adverse impacts on the environment, enhance the living quality of their occupants and local community, while yet continuing to generate adequate profit for developers (Zuo and Zhao, 2014, Olubunmi et al., 2016).

'Green building' is a term that has been used interchangeably with 'sustainable building' and 'highperformance building,' which, as pointed out by Zuo and Zhao (2014), has generated some confusion. Nevertheless, the concept, however described, refers to a "minimization of impacts on the environment, enhancing the health conditions of occupants, the return on investment to developers and local community, and the life cycle consideration during the planning and development process." (Zuo and Zhao, 2014, p. 272) In the context of moving towards sustainable buildings within Australia, sustainability rating tools (or, green rating tools) have emerged key enablers for producing sustainable buildings. Their use is voluntary, going beyond what is required of mandatory instruments, like the National Construction Code (NCC) (Olubunmi et al., 2016, Foong et al., 2017). Sustainability rating tools evaluate buildings and order them by rank, or rating. The rating imputed a building serves as a common language by which stakeholders are given to understand the building's level of adoption of sustainable practices (Gou and Xie, 2017, Li et al., 2017). 
Despite the envisaged benefits of sustainability assessment tools, in reality, sustainability transitioning within the Australian building industry has yet to produce tangible positive results (Van der Heijden, 2016, Foong et al., 2017). This problem has been largely attributed to unfavorable social, regulatory, political, and instrumental realities (Smoleniec et al., 2017, van der Heijden, 2018, Wong et al., 2018). According to Yang and Yang (2015, p. 276):

\author{
"Despite the potential benefits and technological viability, \\ voluntary uptake of sustainable housing is still in its infancy in \\ Australia, mostly driven by motives of experimentation, \\ showcasing and marketing."
}

Clearly, ascertaining the factors — barriers - that are hindering Australia's shift towards adoption of sustainable buildings is timely and relevant (Yang and Yang, 2015). These barriers are largely affected by social dynamics (Foong et al., 2017); specifically, the interactions between individuals within groups, the interactions of individuals with respect to their group, and the interactions between groups (Durlauf and Young, 2001). Indeed, the social dynamics factors inhibiting wide-scale sustainability uptake remain under-researched (Foong et al., 2017, Kivimaa et al., 2017, Smoleniec et al., 2017, Warren-Myers et al., 2018). Mostly, previous studies, including the work by HatvaniKovacs et al. (2018), have identified significant problems, but tend to quantify aspects of the performance weakness of sustainability rating tools.

Of those studies moving beyond the tools dialogue, the focus tends to be narrow. Wong et al. (2018) examined property practitioners, while van der Heijden (2018) looked at the transferability of sustainability awareness from market leaders to mass consumers. As for Warren-Myers et al. (2018), their focus was limited to the consumers of voluntary sustainably certified residential developments.

This paper thus aims to identify the barriers that are thwarting the government's agenda for a 'revolution' towards sustainable buildings in Australia. It does so from a broad social dynamics perspective, where all the interacting elements of the system, reciprocal impacts, and their interrelations are incorporated in the study. Simply, the present study is overdue, since, in the absence 
of a full understanding of the extant barriers, a meaningful and genuine sustainability transition cannot be expected to find traction (Williams and Dair, 2007, Kivimaa et al., 2017).

The study goes beyond the extant literature in examining the issues affecting sustainability transition. It identifies and sheds light onto the weakest links of the chain, and highlights areas hitherto overlooked in previous studies. This has practical implications for both the development industry and government by pointing out current major deficiencies. The findings and recommendations presented here also support policy makers and sustainability advocates on informed decision-making, providing evidence for the necessity of shifting resources and priorities to new fronts, namely, the end-users of sustainable buildings.

\section{Sustainability transition: Background}

As a signatory to the Paris Climate Agreement, Australia has committed to achieve net zero emissions, nationally, by 2050 (ClimateWorks, 2016). Accordingly, Australia aims to reduce emissions to under 28 percent of 2005 levels, by 2030. With Australia's strong population growth rate, this represents at least a 50 percent reduction in emissions per capita, exceeding even the targets set by the US, Japan, the EU, Canada, and South Korea (Australian Government, 2015). The Australian building industry, as the major source of emissions, is an integral element in the program towards reducing emissions (Berry and Marker, 2015b, Warren-Myers et al., 2018, Wong et al.., 2018). The report by ClimateWorks (2016, p. 2), on the contribution that buildings must make in realizing this goal, states:

\footnotetext{
"Even without technological breakthroughs, our modelling indicates that cost-effective energy efficiency and fuel switching can reduce... emissions by more than half... [with] solar PV to eliminate remaining emissions, resulting in zero carbon buildings by 2050.”
}

In pursuing this ambitious target, government has cobbled a strategy of legislating minimal mandatory codes and standards, combined with expectations of higher levels of compliance through 
voluntary uptake, as measured by rating instruments, and incentivized by market demand (Berry and Marker, 2015b, Mcguirk et al., 2015, Smoleniec et al., 2017). NCC, formerly known as the Building Code of Australia, introduced requirements for the thermal performance of the envelope, and the energy efficiency of fixed components, such as water and lighting in buildings (Wong et al., 2018). NCC is therefore a ready-made policy instrument, and the primary method of demonstrating compliance with the mandatory energy efficiency codes (ASBEC, 2018, van der Heijden, 2018). One route to establishing compliance with NCC requirements is the Energy Star Rating Scheme, namely, the Nationwide House Energy Rating Scheme, or NatHERS, which can be undertaken through simulation software (Berry and Marker, 2015a, Daniel et al., 2017, Hatvani-Kovacs et al., 2018). Under the NCC, there is a mandatory requirement that new dwellings meet a six star energy efficiency rating, based on NatHERS (Warren-Myers et al., 2018)

Several voluntary instruments for the reduction of emissions also exist, and these provide certification across a range of sustainability compliance levels (Yang and Yang, 2015, Gou and Xie, 2017, Li et al., 2017, van der Heijden, 2018). These tools (hereinafter referred to as 'green' rating tools) act as complimentary to the mandatory scheme (Xia et al., 2013, Van der Heijden, 2016). These are the products that impute 'green building' status, usually through a rating system, and are the arbiters that determine the extent to which a building can outperform the resource consumption levels set by the minimum requirements of building codes (Mitchell, 2010, van der Heijden, 2018).

The National Australian Built Environment Rating System (NABERS) and Green Star are, according to Mitchell (2010) and JLL and WSP (2015), the two major rating tools in Australia. (Readers interested in details of the wider range of available rating tools in Australia are referred to discussions available elsewhere (Iyer-Raniga et al., 2014, Foong et al., 2017, van der Heijden, 2018).) As argued by JLL and WSP (2015), NABERS and Green Star are by far the most dominant tools within the Australian market. The likelihood of international rating competitors, such as LEED, becoming popular in Australia remains low, particularly given that NABERS and Green Star are now well established (JLL and WSP, 2015). 
The Green Building Council of Australia (GBCA) launched Green Star, in 2003 (van der Heijden, 2018). It is a design rating tool, the system is voluntary, and it relies on existing regulations, but interest in it has been on the rise (Xia et al., 2013). To its credit, it has sought to be adaptive, seeking to assess a range factors (management, environment quality, energy, transport, water, materials, land use, emissions, as well as innovation) as well as tailoring its instrument according to building usageoffice, rental, educational health, and multi-unit residential (Iyer-Raniga et al., 2014). In 2013, it had

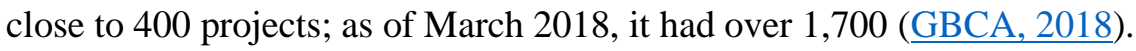

NABERS, a performance rating tool, was first launched in 1998 in NSW, and in 2005 it became a nationwide voluntary instrument to gain insight into the resource consumption of existing buildings (Iyer-Raniga et al., 2014). Under the Building Energy Efficiency Disclosure (BEED) Act, 2010, a NABERS energy certificate is needed for office buildings of 1000 square meters or more, yet no specified level of certification is mandatory (NABERS, 2018, van der Heijden, 2018). NABERS has a relatively high participation rate, close to 77 per cent, in energy labelling of office buildings (van der Heijden, 2018).

Thus, from the outset, a misdirection emerges. Sustainability is more than just the resource usage and carbon emissions of the finished building (Mitchell, 2010). The green building concept encompasses the whole life-cycle of planning, designing, constructing, operating, and even decommissioning and disposal (Zuo and Zhao, 2014, Lu et al., 2017). A holistic vision of sustainable building seeks to absorb building strategies that are less resource-intensive or pollution-producing (Tam and Zeng, 2013). At the same time, the sustainability of the urban landscape is more than the sum of the sustainability of its component buildings; transport, amenities, social fabric and culture, amongst other factors, need to be taken into account (Xia et al., 2015, Jackson, 2016, Doan et al., 2017, Martek et al., 2018). These tools, thus, do not even attempt to measure the whole range of sustainability factors that impact the built environment. Moreover, research studies demonstrate that the contribution of the existing rating tools, both mandatory and voluntary, on improving sustainable outcomes across the factors they do proport to measure, is, at best, marginal (Hatvani-Kovacs et al., 2018, van der Heijden, 2018, Wong et al., 2018). 
This impotency is explained by the persistence of barriers that hinder the sustainability transition movement. In Australia, these barriers occur across a multiplicity of levels (Iyer-Raniga et al., 2014, Berry and Marker, 2015b, Foong et al., 2017).

\section{Sustainability transition: Identified barriers}

The literature identifies a wide range of barriers to sustainability transition in Australia. In catalyzing the process through introducing mandatory low-carbon governance instruments, NCC is relatively lenient on energy efficiency compared against its international counterparts (Iyer-Raniga et al., 2014, Wong et al., 2015). Moreover, implementation is fraught with poor enforcement (Berry and Marker, 2015b, van der Heijden, 2018). Short of strengthening the building codes and upgrading rating systems to reliably measure and verify outcomes, none of Australia's sustainability commitments will be achieved in time (Love et al., 2012, ClimateWorks, 2016). The existing mandatory rating instruments like NatHERS have also come under serious criticism of technical inadequacy, along with a failure to produce tangible positive outcomes (Ambrose et al., 2013, Berry and Marker, 2015a, Foong et al., 2017, Hatvani-Kovacs et al., 2018).

Moreover, with voluntary instruments the rate of participation remains very low; limited primarily to small, niche markets. The corollary is that the majority of the market are not convinced at all of the value of sustainability ratings (van der Heijden, 2018). Specifically, Green Star's product, the existing Green Star rated space, has penetrated less than $0.5 \%$ of the Australian building industry (van der Heijden, 2014). And again, Mitchell (2010) and Xia et al. (2013) reveal anomalies in the way Green Star ascribes ratings across its categories. For example, the Management category accrues the highest percentage of claimed points, with $94 \%$. However, points here can simply be awarded for having a Green Star accredited professional on the management team. On the other hand, points in the Energy category, the principal concern of government, are claimed by only $64 \%$ of Green Star rated buildings. Indeed, Innovation credits are the least claimed, at 35\%, whereas innovation is what the industry needs if the sustainability agenda is to truly progress (Zuo et al., 2013). Overall, 4 Star rated buildings appear to rely on credits for materials usage. Only when energy use is addressed can 
buildings achieve 6 Stars; yet ironically these comprise only $14 \%$ of all rated buildings (Xia et al. 2013).

Additionally, there are industrial barriers. Though ASBEC (2018) warns that 58\% of the buildings that will be in place in 2050, are yet to be built, the existing building stock in Australia mainly predates the 1980s, built long before the introduction of any energy efficiency regulation or scheme (Sandy, 2011). A typical Australian home has an area around $200 \mathrm{~m}^{2}, 3-4$ bedrooms, and several space heaters and coolers, with low energy efficiency and a high rate of carbon emission (Saman, $\underline{2013)}$.

Organizational and procedural issues, as well, retard the uptake of sustainability practices (Hakkinen and Belloni, 2011). Projects may lack personnel with relevant skill sets, environmental management systems may not be implemented, and marketing may be ineffective (Zuo and Zhao, 2014). Buy-in or behavioral practices also fall short. Clients, designers and occupants are far from persuaded of the merits of green buildings (van der Heijden, 2015, van der Heijden, 2018). Even when sustainable building practices are incorporated into an office, the benefits appear more psychological than substantial; feeling 'good' about being green - though even the materialization of this meagre benefit is contested (Rashid et al., 2012).

Despite the value of the above studies in identifying sustainability transition barriers, their efforts have in the main concentrated on technical features and performance issues of sustainability rating tools (Xia et al., 2013, Hatvani-Kovacs et al., 2018). The rating tools are, however, designed to engage consumers, and as such, the primary intended outcomes of these rating systems have been overlooked in previous Australian studies (Warren-Myers et al., 2018). Moreover, of those studies that have paid attention to consumers, they have not considered the strong influence of interactions among power groups, individual group members and the reciprocal impacts between individual interactions and group level behaviors. Simply, the impact of social dynamics has been missing from the examinations of existing literature (Foong et al., 2017). Previous studies like Wong et al. (2018) and Warren-Myers et al. (2018) have targeted specific stakeholders in isolation, with the major focus being on market leaders rather than mass consumers (van der Heijden, 2018). Indeed, the residential 
building market, and the ordinary consumers who need housing, have simply not received the attention they deserve(van der Heijden, 2014, Warren-Myers et al., 2018).

Mostly, the built environment is residential, and mostly the end consumer is the home-owner or home-renter. This is where the greatest divide lies (van der Heijden, 2014). It is exacerbated by enduser confusion (Mitchell, 2010, Hall, 2014), where the manner in which information is provided is practically meaningless to the average person (ASBEC, 2016, ClimateWorks, 2018). Reaching and persuading the end-user of the value and merit of sustainability, therefore, seems yet a long way off (van der Heijden, 2015).

\section{Sustainability transition: The theoretical lens}

A sustainable building industry, pursues sustainable technologies and techniques and sustainable production processes, has green buildings as its products, and consumes in a sustainable manner ( $\mathrm{Li}$ et al., 2017). Achieving this objective in a certain country is in line with the definition of the 'sustainability transition' phenomenon, and research on this topic falls within the 'transition research' arena (Truffer et al., 2015). Sustainability transition offers an emerging and recent theoretical lens, well suited to describing the transition towards sustainability within socio-technical systems like the building industry (Foong et al., 2017). Sustainability transition represents a "long-term, multidimensional, and socio-technical systems shift to more sustainable modes of production and consumption." (Markard et al., 2012, p. 956) This framework was found to be in direct alignment with the objectives of this study. That is, the framework is capable of incorporating social dynamics, as well as technical elements, such as low-carbon governance instruments (Markard et al., 2012, Foong et al., 2017). The framework was therefore selected as the theoretical lens informing the present study. Successful application of sustainability transition in conducting the study by Foong et al. (2017) supported this decision, attesting to the value of this theoretical lens in being able to capture social dynamics, as well as, instruments in empirical studies of the building industry. Three main dimensions are utilized in the sustainability transition framework for mapping the transition contours. These comprise (1) socio-spatial embedding, (2) multi-scalarity, and (3) issues of power (Truffer and Coenen, 2012, Truffer et al., 2015), as illustrated in Figure 1. 
Socio-spatial embedding engages with the social dynamic context in which the transition is supposed to occur (Truffer et al., 2015). It represents a synthesis of locally embedded contexts of events, objects and actions affected by wider socio-political, institutional and cultural factors (Gibbs and O’Neill, 2017). Of particular interest are specific cultures, political systems, institutions, existing networks and capital stocks that make the context more or less amenable to sustainability transition, along with the capability of influential actors to accept the transition in the form of new working style or policies (Markard et al., 2012, Truffer and Coenen, 2012).

\section{<<Insert Figure 1 about here $>>$}

Figure 1. The theoretical lens of the study

Multi-scalarity conceptualizes the niches, and perceptions of transition as emerging and interacting that form multi-scalar structures (Truffer et al., 2015). Multi-scalarity denotes the existence of different scales like time, structure, space, and therefore is concerned with the number of interactions that need to be considered across these scales (Raven et al., 2012). Issues of power is predominantly concerned with the question of 'who'. This engages with sustainability transition from the perspective of 'who loses', 'who gains', 'who sets the agenda' (Foong et al., 2017). In fact issues of power define 'whose voices, concerns, and socioeconomic and environmental conditions are more or less heard, addressed, and improved through transition initiatives." (Truffer et al., 2015, p. 65)

\section{Research methods}

Primarily, qualitative methods are effective approaches in addressing issues within real-life settings (Dainty et al., 2000). The two prominent methods of collecting qualitative data comprise participant observation; typically in focus groups, or through individual interviews (Morgan, 1997). Of these, focus groups are capable of capturing the interactions and actors' influences, based on their real-life roles (Morgan, 1997, Morgan, 2012). This is quite in line with the objectives of the present study, which seeks to incorporate the social dynamics of the context. Besides, focus group discussions allow 
respondents to share views on a problems at hand, to inform future decision-making (Morgan, 2012). The method also enable researchers to generate detailed, rich data on complex matters which require granulated, nuanced understanding (Dimitriadis and Kamberelis, 2013). All these facts provide support for selecting focus group as the primary method of qualitative data collection in the present study.

\subsection{Focus groups}

Exploiting pre-existing networks contributes to the success of a focus group, particularly where participants share common goals and are engaged in a common activity (Dimitriadis and Kamberelis, 2013). Following this precedent, focus group participants for the present study were drawn from the Australian green building community, representing a cross-section of roles and a variety of influential institutions. This is tabulated in Table 1. As seen in Table 1, the demographic profile of the focus groups is replete with expertise in the sustainability area. Indeed, effective focus group composition occurs when members are comfortable talking to other participants and share similar interests in the research problem (Dimitriadis and Kamberelis, 2013).

Table 1. Profile of the focus group members

\begin{tabular}{|c|c|c|c|}
\hline $\mathrm{ID}^{*}$ & Position in the industry ${ }^{* *}$ & $\begin{array}{l}\text { Experience with } \\
\text { sustainable } \\
\text { buildings (years) }\end{array}$ & $\begin{array}{l}\text { Involvement with sustainability } \\
\text { transition }^{* *}\end{array}$ \\
\hline M1 & $\begin{array}{l}\text { A leading expert in building } \\
\text { energy efficiency }\end{array}$ & 40 & $\begin{array}{l}\text { Member of a federal government } \\
\text { advisory committee on energy } \\
\text { efficiency }\end{array}$ \\
\hline M2 & $\begin{array}{l}\text { An instrumental member in } \\
\text { numerous regional } \\
\text { sustainability initiatives }\end{array}$ & 20 & $\begin{array}{l}\text { Sustainability tool trainer and assessor, } \\
\text { member of an environment committee, } \\
\text { active in developing and promoting } \\
\text { several green communities rating tools }\end{array}$ \\
\hline M3 & $\begin{array}{l}\text { Leader in several } \\
\text { sustainability consultation } \\
\text { organizations }\end{array}$ & 10 & $\begin{array}{l}\text { Sustainability leader and advisor in } \\
\text { three organizations }\end{array}$ \\
\hline M4 & Head of energy assessments & 10 & $\begin{array}{l}\text { Head of Assessments and project } \\
\text { manager of sustainability projects in } 3 \\
\text { organizations }\end{array}$ \\
\hline M5 & $\begin{array}{l}\text { Founder of a sustainability } \\
\text { community }\end{array}$ & 20 & $\begin{array}{l}\text { Founder of sustainable community, } \\
\text { sustainability tools accredited } \\
\text { professional, sustainability ambassador } \\
\text { and facilitator }\end{array}$ \\
\hline M6 & Energy Inspector & 5 & $\begin{array}{l}\text { Energy inspection practitioner and } \\
\text { researchers }\end{array}$ \\
\hline
\end{tabular}


M7 Prize-winning architect

M8 Director

M9 Director

Member of sustainable committees

M11 Sustainability consultant

M12 Board member for a green development forum

S1 Director

S2 Director

S3 Head of transformation committee

S4 Researcher in a major sustainability research center

S5 Environmental consultant

Teaching and research on sustainability

S7 Teaching and research on sustainability

Director of a sustainability advocacy organization

S9 Sustainability judge and advisor

Member of the advisory

S10 committee for several green rating tools

Director of a sustainability

S11 international institute in the region sustainability research center

International sustainability adviser, speaker and consultant, and international writer on cities and the environment.

$\mathrm{CEO}$ of three consultancy firms and head of marketing for a solar company Director of a consultancy firm providing sustainability services and advice

Associate of the council active in property economics and sustainability in Victoria and member of two committees on sustainability

Senior sustainability tools accredited professional

Senior expert with three consultancy firms and one construction company Founder and director of a sustainability tool consultancy company Founder and director of sustainability tool consultancy company and a member of the steering committee member for promoting excellence in sustainable architecture

Marketing and transformation, advisory committee for a major sustainability rating tool

Conducting research on the performance of green rated buildings

Senior Sustainability advisor and environmental consultant in tertiary education

Member of a sustainability and environmental quality research institution

Conducting research on sustainability in the built environment

High-rankled managerial positions in a major sustainability advocacy group in Australia and advisor of major green rating tools

General Manager of a major sustainability center, sustainable events consultant, auditor \& trainer and researcher in a major research institute

Architect and principal consultant sustainable design

Leading sustainability issues in Australia and NZ across the built environment

Senior researcher on sustainability 
Coordinator of a major

S13 sustainability organization

funded by the government

S14

Director of a sustainability advocacy group
Case manager of sustainability on large-sized infrastructure projects and a member of a sustainability council in Australia

Founder and director of a company active in sustainability and ecology; principal researcher on sustainability in the built environment

Notes: ${ }^{*} \mathrm{~S}$ stands for Sydney and $\mathrm{M}$ for Melbourne, referring to the location of the two focus groups; ${ }^{* *}$ Descriptions are slightly altered to maintain the anonymity of participants.

\subsection{Data collection}

Australia continues to follow a 'two-speed economy' trend, with Victoria and New South Wales persisting as the hubs for construction, with other states observing major slumps in building and construction activity (ACIF, 2018). Two focus groups sessions were held, with Sydney and Melbourne thus selected as the appropriate locations, conveniently attracting a greater range of experts from the Australian construction industry. The focus groups in Melbourne and Sydney had 12 and 14 participants respectively, both within the acceptable range of 6 to 15 , as recommended by Morgan (1997). The common cited guideline in the literature demands at least two groups for studies relying on focus groups data (Guest et al., 2017). This requirement is therefore met in the present study.

The focus group sessions started with the moderator, posing two general questions to the group and encouraging all participants to generate responses, views and opinions pertaining to the objectives of the present study. The general questions were:

1) How successful has the transition been in Australia towards a sustainable building environment?

2) What opportunities and barriers make the Australian building industry more or less amenable to such a transition?

The sessions were managed with the aim of generating data out of the interactions and arguments, rather than intervening in order to impose unity or consensus, with discussion at times quite heated. All interactions and discussions were voice recorded in sessions lasting 4-5 hours. Moreover, participants used notes, diagrams and frameworks when discussing their views and as instruments to 
clarify arguments, points and summations. All such notes, tables, figures and diagrams, as generated on whiteboards and flip-chart sheets - see Figure 2 as an example - were collated and analyzed. The recordings were converted to transcripts, along with the other forms of output generated during the sessions.

\section{$<<$ Insert Figure 2 about here $>>$}

Figure 2. Examples of data generated in focus groups

\subsection{Data analysis}

The analyses extracted meaning from the collected data, generating themes that could be contextualized within a theoretical framework. This was done by coding the transcripts and other session generated artefacts. The sustainability transition theoretical lens, as illustrated in Figure 1, was the basis for coding, using Nvivo 11. Software packages, such as Nvivo, enhance the rigor of data analysis outputs in qualitative studies, and offer a fuller insight in the analysis process (Bazeley, 2013). Coding stands at the center of all qualitative analysis, and close attention is required to the matter of generating codes (Lewins and Silver, 2007). An effective method to extract meaning through coding interview transcripts entails centering on similarity, comparison, and contrast, against a priori codes (Bazeley, 2013). Thus, this is the approached used in this study, with the objective being to give meaning to the data within a theoretical concept (Lewins and Silver, 2007). This form of qualitative analysis is termed by Merriam (2014) as 'analytic induction' in which researchers produce a right fit between their data and a formulated explanation of the phenomenon under question. The three dimensions outlined in the sustainability transition theoretical lens in Figure 1 were used as the initial point of departure in coding the data. This approach greatly facilitates ensuring that the information embedded within the transcripts are linked to an established paradigm, while also generating fresh ideas (Bazeley, 2013).

\section{Data analysis and findings}

Analysis of interview transcripts brought to light several major findings with regard to the sustainability transition, as presented below. 


\title{
6.1.Sustainability rating tools: The essential step
}

Despite critical views on rating tools, discussions indicated that the existing rating tools, though fraught with many shortfalls, are much needed. They were viewed as an essential first step in overall movement towards a more sustainable building industry. That is, adopting the existing rating tools has facilitated the sustainability transition within the Australian context: increasing awareness, raising outcomes, providing an integrated framework for sustainability concerns and a common language for the industry.

\author{
"Sustainability [is] a journey and that the rating tools are \\ elements on that journey you have to have in place to get to the \\ next step." (Participant S2)
}

Beyond the tools themselves, discussions centered on the absence of supporting mechanisms in Australia to complement, increase uptake, govern, and refine existing rating tools. As such, a large number of barriers were revealed that hinder the transition to a more sustainable building industry, in which rating tools were axiomatically assumed to lie at the core.

\subsection{Barriers hindering the sustainability transition}

Various barriers emerged under each of the three main dimensions of sustainability transition framework. Figure 3 summarizes the nature of these barriers, revealed based on coding of the qualitative data. The relative importance of each code was assessed in view of the number of references to each code. Treating the number of references to codes as an indication of their weight or relative importance is a common practice in analyzing qualitative data in construction research (Chileshe et al., 2016). Such inference is defensible, given that "people repeat ideas that are of significance for them." (Bazeley, 2007, p. 77) A description of the codes under each dimension of sustainability transition is presented next.

\section{<<Insert Figure 3 about here $>>$}

Figure 3. Barriers to sustainability transition in the Australian building industry 


\subsubsection{Socio-spatial embedding}

As a result of analyzing the qualitative data, 4 barriers were found to be associated with the sociospatial embedding dimension of social transition within the Australian building industry context, a description of each one is provided below.

\subsubsection{Lack of end-user demand}

Lack of demand from end-users of buildings was found to be the most serious problem under the socio-spatial embedding dimension, with 145 references (see Figure 3). This barrier was attributed to 4 main reasons that diminish the demand for sustainable houses among the end-users of buildings in Australia. Of particular importance was the lack of access to user-friendly information by ordinary users, where the existing forms of available data and information generated by low-carbon governance instruments are not fully understandable for ordinary end-users of the building industry. In essence, the currently available data do not enable building end users to make a link between what they expect from houses, with the performance of sustainable houses and sustainable building.

With such lack of supportive data to motivate end-users, no real incentive exists to enhance the level of demand in the market for green buildings. As the most well-known feature of sustainability, energy prices and energy savings associated with it are not real motivators for end-users, as is sometimes suggested.

\footnotetext{
"Around 2 percent of household income across Australia is spent on energy bills...so it's not a huge cost. So, when you talk about behavior change, it happens when the price of staying the same is greater than the price of changing." (Participant S5)
}

There was agreement that cultural sustainability in a community is a major driver for sustainability transition, when it becomes a part of the culture of the community to actively engage in efforts to promote various dimensions of sustainability. The arguments were indicative of the fact that such cultural sustainability is not strong enough to drive demand for Australian end-users, particularly compared to leading countries like Germany. 
"We really need that culture, that vision and we talk about how in

Northern Europe and Germany there is a much stronger culture,

here we don't have that." (Participant S6)

A part of the problem was also attributed to the issue of housing affordability in Australia, making end-users focus on purchasing anything they can afford, rather than looking for particular features like sustainability as a criterion for selection.

"The market is so hungry [that] you don't have to build something special for someone because they buy anything."

(Participant S1)

\subsubsection{Lack of awareness}

The lack of awareness was discussed extensively. This was seen a major barrier, as well as the source of other barriers to sustainability transition. As illustrated in Figure 3, lack of awareness was predominantly seen as an end-user problem with 63 references, compared against policy makers (11 references) and industry practitioners (5 references).

\section{"I think that the key problem is: understanding outside the domain of sustainability practitioners." (Participant M1)}

The arguments, however, indicated that various levels of the industry and policy makers are similarly affected by misunderstandings and misconceptions about sustainability in the building industry. There was consensus that the level of knowledge of builders, and people in charge of advertising and selling properties in the building industry has a profound impact on end-user awareness.

\subsubsection{User behavior}

User behavior was discussed as an influential factor that determines the outcome of all movements toward sustainability transition. That is, the final outcome of the sustainability movement is defined by the behavior of the user, regardless of the quality of houses, or the number of stars given to a house based on sustainability assessment tools. The user has a pivotal role in making the sustainability transition work or fail. With the acknowledged lack of awareness and lack of access to information, 
user behavior was identified as a barrier hindering the achievement of the aims of the sustainability transition within the Australian building industry.

\author{
"The missing part of all of this is occupant behavior, because all \\ of this gives you potentially sustainable buildings and until people \\ learn how to live and work and reside in buildings well, 6 star \\ building can be ...you know ...horrible ...can be operated by a \\ two star tenant in a terrible way." (Participant S3)
}

\title{
6.2.1.4. Complacency
}

There was agreement that a prevailing assumption of the abundance of the land and resources along with the benign climate in Australia have fostered an overall sense of complacency and security. These have accordingly eclipsed the urgent need for taking action on issues related to improvement in the building industry, including the essentiality of sustainability transition in the building industry.

\author{
"The biggest problem for me is the great Australian complacency \\ ...We have it so good. In the property market, it doesn't matter \\ and we have this amazing environment and clean water...so \\ adding a bit of pollution doesn't really matter." (Participant S5)
}

\subsubsection{Multi-scalarity}

Various disjointed elements in the market act as barriers to materializing sustainability transition across the Australian building industry. In fact, a serious problem of the current sustainability transition movement is its failure to enter various markets, and equally engage across niches, regimes, practices, lifestyles and locations. Three main disintegrations were identified (see Figure 2); a description of which follows.

\subsubsection{Fragmented market}

The most serious fragmentation was found to be the residential market in Australia, particularly compared against the commercial one. The causes of such fragmentation are the differences in energy prices, mandatory disclosure requirements, the return on investment for sustainability modifications, 
and competition among developers in the commercial sector. Overall, the hunger for residential housing remains the major inhibitor of sustainability transition diffusion in the residential market.

The diverse and social-economic status of customers and the ownership model in the residential market is another major problem towards integrating the residential sector into the movement of sustainability transition. The lack of 'point of sale' disclosure program was mentioned frequently as the major drawback with the residential sector.

$$
\begin{aligned}
& \text { "In commercial here ... they hold it for } 30 \text { years... They see ROI. } \\
& \text { The average household sees a cycle in } 6 \text { or } 7 \text { years ...So I have } \\
& \text { heard people actually say, we are not going to buy a solar water } \\
& \text { system for the new owners to benefit." (Participant S7) }
\end{aligned}
$$

One major barrier hindering sustainability transition was associated with the level of focus. Despite availability of several rating tools to assess sustainability on the community or neighborhood scale, attempts for the major part have concentrated on single buildings as the level of interest. As a result, overall sustainability has been scaled down to a single building, which does not cover the aims and objectives of sustainability. In fact, a single house, regardless of how 'green' it is rated, can result in unsustainable outcomes, given its location, lack of local facilities and amenities, or town planning regimes. From a broader perspective, even simplest objectives like energy and carbon reduction are not met in such circumstances, through the house is highly rated as an individual unit.

$$
\begin{aligned}
& \text { "If I say to someone invest this this this in your house when you } \\
& \text { build it and it will be efficient and they find that they save } 20 \\
& \text { dollars a year, then I have over sold it ...even though I might say, } \\
& \text { well you're not in the right piece of land because it's not a } \\
& \text { infrastructure area and you are not behaving properly and you } \\
& \text { are driving } 40 \mathrm{KMS} \text { to work." (Participant M7) }
\end{aligned}
$$

There was agreement that sustainability transition has become a reality only in the high-end office blocks, in the central business districts (CBDs) of major Australian cities, beyond which the impact of 
sustainability assessment tools has been negligible. As such, a barrier still hampering sustainability transition is the failure in diffusion of sustainability uptake beyond the narrow 'top-end-of-town' niche.

\author{
"In the bigger end of town people are using [green rating] to \\ compete for selling space, and in the other end of town [people] \\ can't afford it." (Participant S6)
}

\title{
6.2.2.2. Sustainability silos
}

Sustainability silos was the terms used by participants for describing the disjointed nature of attention to the various sustainability dimensions. This was a much-emphasized barrier under the multiscalarity umbrella for which the number of references was equal to the barrier 'Fragmented Market.' In discussing the barrier, there was strong focus on the lack of linkages, and uneven attention to various dimensions that make the building industry sustainable. At the forefront of the discussions was the need for integrated approaches to energy, carbon reduction, affordability, community welfare, health and safety, household wellbeing and comfort, to fully embed sustainability in the Australian building industry. Given the dominant mindset behind designing the sustainability assessment regimes, to date, an integrate approach is still missing.

In particular, priority has been given to technical features of buildings at the design stage. There has been too much focus on the energy efficiency of designed models, and as such, current practices in promoting sustainable transition was described as 'mechanistic' by many participants. This approach, favoring hard and reductionist features, prioritized the building design stage, yet lacks a holistic vision to sustainability, presenting a key barrier to the spirit of sustainability transition.

\footnotetext{
"Carbon is [...] only one particular section of the impact the building has [...] where are the materials coming from [...] the impact on the environment where we have taken the resources from and...?" (Participant S7)
} 


\title{
6.2.2.3. Varied jurisdictions
}

Given the political system of Australia and the hierarchy of government, each jurisdiction varies in terms of its arrangements for sustainability transition. The level of expectations, the sustainability assessment regime and regularity requirements are varied. This variation of jurisdiction is exacerbated by the glaringly different climates in Australia that make the outcome of current sustainability assessment tools different in terms of effectiveness.

\author{
"Building acts are state based mentalities and you get different \\ approaches in each state and Vic will do things differently and \\ $N S W$ will do it differently and that's a serious problem and we \\ need national if you are going to bring any sort of umbrella we \\ can work under." (Participant M10)
}

\subsubsection{Issues of power}

Arguments resulted in conceptualizing the power relations affecting the sustainability transition in the Australian building industry. The role of exiting influential powers were critically evaluated and the barriers associated with those powers were discussed. As illustrated in Figure 2, the performance of various actors and powers in the market were seen as barriers to sustainability transition in the building industry, as discussed below.

\subsubsection{Passive government}

The government was criticized for its passive approach in promoting the agenda of sustainable transition across the Australian building industry, leaving everything to the market and industry.

"It has to be within a framework, free market doesn't do it completely.” (Participant S1)

In light of the potentially highly influential impact of government on the market, the major fallout of this passive approach to sustainability transition was conceptualized under the four categories, below. 


\title{
6.2.3.2. Low regularity requirement
}

The requirements of national building codes pertaining to sustainability transition of the building industry were described as inadequate, and at best, minimal, compared to other developed countries. And raising the level of expectations, in the form of regulatory requirements, was seen as a task long overdue of the government bodies in charge.

$$
\begin{aligned}
& \text { "I agree that the regulatory frameworks aren't adequate ... and } \\
& \text { personally after all my time in this and I contributed to that... I } \\
& \text { think they should be elevated." (Participant S5) }
\end{aligned}
$$

That is, there was agreement that regulations on their own cannot be the ultimate solution; regulations were described as setting the 'floor' for the regime for which voluntary sustainability rating tools can become the 'ceiling.'

\author{
"Regulation actually is important because there are plenty of \\ builders who won't do anything unless they have to. That's it." \\ (Participant S7)
}

\subsubsection{Lack of vision}

The government was also criticized for lacking a long-term vision and strategy in addressing the issues of sustainability within the Australian building industry. The lack of big picture and an ultimate goal was emphasized, where the broad picture has been scaled down to several small tools being applied in various sectors and markets. There is no deadline to fulfil the objectives and the ultimate target, if any, is not clearly communicated.

\footnotetext{
“We need to reduce greenhouse gases and that's all it says ... and that's the problem - we haven't got a target, we do not have a timeline ...reduce from what? We haven't got a target that say we are going to produce zero carbon building by 2028." (Participant M2)
} 
Failure of the government in defining and enforcing an umbrella framework that directs and governs all attempts in the field and prioritizes the tasks with definite timeline and milestones was identified as a major barrier by the participants. Against the backdrop of economic growth agenda and the increasing population, lack of such an overarching framework was described as disastrous for the Australian context.

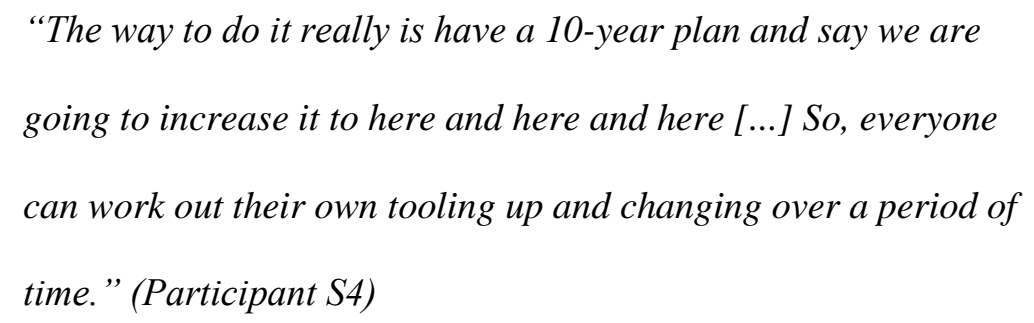

\subsubsection{Lack of audit}

There was emphasis on the lack of an effective auditing mechanism. It was asserted that even with minimum regulatory requirement, there is no policing and auditing to make sure the requirements have been fulfilled. The participants stated that the absence of auditing mechanisms can diminish accountability for sustainability transition, and as such, render efforts in the design stage with regulations, futile.

\section{"Then there is the lack of accountability for insuring that what was designed or the philosophies that went into the design has been achieved." (Participant M3)}

\subsubsection{Ineffective Green Marketing}

One barrier frequently mentioned by participants was the ineffectiveness of marketing strategies to sell the idea of sustainability to the building industry in Australia. With 64 references, this factor was the second most important barrier after 'passive government.' Participants maintained that the existing marketing strategies are unattractive for a majority of consumers; the information provided is not in alignment with true requirements and priorities the people affected.

"You have to sell sustainability to everyone in their own terms

[...] that is a potentially problem for us practitioners."

(Participant S1) 
With the above in mind, the market has failed at convincing consumers that purchasing sustainable houses will benefit them, even with regard to delivering cost savings to them. And consumers cannot see their priorities among the advantages mentioned for sustainable houses. The major problem was found to be with the approach taken by real estate agents. The absence of useful information related to sustainability of house on real estate websites to justify the superiority of sustainable house was seen as serious barrier to an effective marketing strategy that promotes sustainability transition.

\author{
"It's got to be fashionable, it's got to be sexy, [...] there are a \\ number of companies out there using that to sell their houses, they \\ are actually using it as a market ploy and people like it [...] they \\ like the idea that they are being good without costing much." \\ (Participant S10)
}

\title{
6.2.3.6. Lack of Leadership
}

Lack of leadership, namely, nobody owning the problem, and the current divergence and separation among various attempts and sustainability frameworks was mentioned as another major problem under the issues of power umbrella. Lack of leadership was used to refer to lack of an entity to bring all valuable attempts and frameworks under one umbrella, and make them converge in terms of purpose and implementation.

\section{"Nobody currently accesses them as a unit of things to look after because no one wants to take responsibility for the whole thing."}

(Participant M11)

\subsubsection{Vested Interests}

The vested interest of various groups were also found to be a barrier inhibiting the movement towards a more sustainable housing in Australia. Industry lobbies and developer groups resist elevating the minimum regulatory standards, drawing upon the housing affordability as their justification. 


\title{
"But raising it [regulatory requirements] high is hard because \\ there are lots and lots of industry groups [saying] you cannot \\ afford to do it! You cannot afford to do it!" (Participant S11)
}

Moreover, it was discussed that energy companies alongside government are not sincerely interested in promoting the agenda for sustainable house that consume less energy.

\author{
"Market and the government will not put money into that area of \\ the market because it's a cash cow for them, they are making too \\ much money out of people using a lot of electricity." (Participant
} S4)

It was mentioned that only an overall movement by people, due to an increased level of awareness and education can convince the government to resist the pressure form industry groups and make a change. The industry intends to stick to the current regime, having Green Star as the sustainability rating tool and improving it slowly. The system needs a real interruption to accept the change and such a change is only justified when the community asks for it.

\section{Discussion}

\subsection{Barriers to sustainability transition}

Two parallel scenarios are currently vying against each other as they play out in Australia. On the one hand there is the hard reality that building stock is increasing rapidly; at unprecedneted levels. On the other hand, for Government (or at least pockets within Government) and its sustainability allies, there is the hope of reducing carbon emissions to zero. These two scenarios are wholly at logger-hards with each other. Certainly, without an effective solution, the sustainability vision will be drowned out by a sea of new, far-from-carbon-neutral buildings, delivered to serve Australia's burgeoning population. Indeed, the evidence is overwhelming that Australia is already falling short of necessary targets in transitioning to a sustainable building industry (van der Heijden, 2018). The research conducted breaks new ground in identifying the barriers impeding that transition. 
This study provides a unique examination of Australia's built environment sustainability transition requirements. It does so against the background of Australia's transition ecosystem, and unlike earlier studies, incorporates and evaluates a comprehensive range of sustainability elements. Most existing research examines the details of low-carbon governance instruments in facilitating the transition. These aim at exploring and uncovering weaknesses, suggesting improvements. This study also speaks to the concerns expressed in previous research regarding the leniency of existing tools (Iyer-Raniga et al., 2014), and acknowledges their technical shortcoming (Hatvani-Kovacs et al., 2018), however, it goes beyond this focus by placing the role and impact of low-carbon governance instruments within the wider context of the sustainability transition eco-system within which these operate.

Consequently, for all their identified weaknesses, the most serious barriers to effective sustainability transition lie comparatively less with the rating instruments but are to be found within the social dynamics of the sustainability ecosystem itself; vested interests exploiting ineffective transition regimes. Recent work by Wong et al. (2018) has raised the issue regarding one type of stakeholder the real estate agent. The actors' chain of stakeholders is however large, and actors must not only play their part to fulfil the requirements of issues of power for sustainability transition, but perform in concert with others if the cause of sustainability is to be progressed. Findings here corroborate and extend the findings of Martinaitis et al. (2015), whose message is that energy consumption in houses strongly depends on occupancy profile, and knowledge must be shared equally and transparently across the various stakeholders, with systems put in place to effect full information flow. In short, this study calls for a shift of priority from further honing low-carbon governance instruments to one of generating and improving sustainability understanding and buy-in from all the various actors in the sustainability domain - particularly the neglected end user.

Issues with multi-scalarity of the ecosystem are also acknowledged in this study. These issues have resulted in the greatest segment of the building industry - the residential market - effectively left out of low-carbon governance instruments; a point argued by van der Heijden (2014). Here too the source of the problem, namely lack of end-user demand, is identified, in accordance with the findings of Wong et al. (2018). Moreover, this study highlights the necessity of effective green marketing with an 
emphasis on providing user-friendly information to the actors. Indeed, only with the substantive activation of actors, each with its own complex arrangement of sub-groups, can sustainability transition be expected to work. Low-carbon governance instruments, regardless of their technical effectiveness, have not succeeded in engaging end-users. What should also be evident is that the enduser is the essential player in this drama yet remains far removed from the grand instigators of sustainability transition - the Paris accord and the Australian federal government. It is this cohort that has been largely ignored.

Overall, the message to be communicated through this study is that while Australia's commitment to zero-carbon emissions is bold and visionary, it is let down by a complete lack of leadership in effecting this sustainability transition vision across the Australian building industry. No identifiable entity owns the problems. While sustainability requires a holistic all-encompassing strategy if it is to be effective, the market is highly fragmented, and without cohesion. Regulations are idiosyncratic across municipalities, rating systems speak past each other, consultants are mixed in their remedies, and the market itself is highly stratified, particularly across commercial and domestic lines. Secondly, and most critically, residential end-users just do not care. They are foremost absorbed by the burden of housing affordability, and without relief there see sustainability as elitist and indulgent. There is little accessible information on the relevance of sustainability to them, and no incentive to subscribe to the vision. Compounding this complacency, government is taking no active leadership role in its own sustainability mission. It is leaving the matter to the market, with little cohesive guidance to stakeholders on how to proceed; no centralization, low regulatory requirements, and tokenistic auditing. The market then suffers from conflicts of interest, where rating providers, building owners, and the parties that provide certification, find themselves bound together in a dependent relationship, and without accountable oversight. This leads to a final point: power. In the absence of government leadership, the sustainability landscape has devolved into spheres of vested interest; consultants, rating providers, developers, and building users and consumers, see each-others' ambitions as encroaching on their own. In sum, a fragmented sustainability market is populated by vested interest silos, operating in a vague, leaderless landscape. 


\subsection{Adopting cleaner production}

In transition to sustainability, much has to be done in order to make the building industry in Australia adopt the cleaner production techniques (ANZECC, 1998, Vieira and Amaral, 2016). Cleaner production principles must affect the way buildings are designed as developments, managed as an industry, and used by occupants - users. According to the cleaner production strategy for Australia recommended by ANZECC (1998), five practical steps towards sustainability transition must be taken: developing a vision, providing technical and financial assistance, establishing a consensus on the need for cleaner production, establishing programs, and assessing the existing system. Findings of the study demonstrate that while cleaner production steps in terms of developing a vision (low-carbon commitments) and providing assistance (mandatory and voluntary tools and incentives for sustainability compliance) are made, the three remaining practical steps have not been successfully followed. With this in mind, this study has several implications for theory and practice concerning the barriers facing following these three clean production steps, for the first time from a broad social dynamic perspective. First, the study contributes to the field, proposing that the blame is to be shifted from low-carbon governance instruments to the social dynamic issues within the transition ecosystem. Second, the study identifies the most serious problem, the fact that residential end-users, owning the largest share in the market, are effectively disengaged from the nation's sustainability cause, and have yet to join the sustainability transition movement. That is, the step towards creation a consensus on the need for cleaner production is not made. Third, the study points to the sources of such problems in detail: there are issues of power among major key players, the socio-spatial embedding is not supportive, and no entity takes the lead in addressing the problems. The clear message for policy makers and practitioners is that instead of focusing on evaluating low-carbon governance instruments, top priority must be given to improving social dynamic features of the sustainability transition ecosystem to engage key actors, with a particular focus on including end-users in the residential market. The focus therefor must shift from providing assistance and developing vision as cleaner production steps towards establishing consensus among all stakeholders on the need for cleaner production and establishing programs to fulfil this objective. 


\section{Conclusion}

Commonly, sustainability transition has been viewed as a technical challenge. Rating instruments are needed to measure building performance, and new materials and techniques are needed to ensure better embodied energy and carbon emissions compliance. Moreover, the building value chain has to be examined in its entirety, from resource acquisition all the way through construction, operations and maintenance, to decommissioning, demolition and disposal. All these steps, too, have been understood as technical challenges. Within this paradigm, government fixes the vision, councils followed suit with set targets, and sustainability consultants flourish in the emerging space to offer advice and guidance. Yet progress towards sustainability in Australia has stalled. Previous research on barriers to sustainability have operated within the 'technical challenge paradigm.' Insufficiencies in current instruments and practices have been many, with the large body of publications on the topic offering proof. Yet remedial measures have failed to redress the situation. The reason for this stagnation lies in the fact that transition to a more sustainable built environment is fundamentally a social challenge. Technical solutions are predicated on social will to find solutions. Without critical social momentum to buoy the sustainability agenda, behavioral change cannot take effect. This underlying barrier is the key finding of this study.

Thus, this study adds significantly to the current body of knowledge on sustainability implementation barriers, focusing on social dynamic of the context. This approach expands the causal net beyond technical considerations to capture the deeper, social factors impacting Australia's sustainability transition mission. Consequently, the findings are also unique in terms of informing policy makers. The arguments presented here challenge the current dominant narrative that it is technical issues that are limiting progress. This study, rather, concludes that technical problems are merely a symptom of a deeper, underlying social malaise preventing effective problem-solving from taking place.

Despite the contributions, there are limitations. One limitation comes from its qualitative nature, relying on 'expert-opinion,' rather than drawing upon hard evidence. Second, in identifying the lack of barriers, like user engagement, the study raises several obvious questions- - what can be done to bring them on board? These questions and the necessity of validating the findings in exposure to hard 
data and broader sample sizes of experts will be the focus of continuing research in subsequent planned studies.

\section{Acknowledgement}

This work was funded by the Integral Design Futures (IDF) funding scheme's 2017 program:

Charting Pre-Design Sustainability Indicators (School of Architecture and Built Environment, Deakin

University).

\section{References}

ABS. 2018. Building Approvals, Australia [Online]. Australian Bureau of Statistics. Available: http://www.abs.gov.au/ausstats/abs@.nsf/mf/8731.0 [Accessed 27 February 2018].

ACIF. 2018. Construction Industry Leaders Forecast a Healthy Recovery in Non-Residential Building Activity [Online]. Australian Construction Industry Forum (ACIF). Available: https://www.acif.com.au/forecasts/summary [Accessed 14 February 2018].

Ambrose, M.James, M.Law, A.Osman, P. and White, S. 2013. The Evaluation of the 5-Star Energy Efficiency Standard for Residential Buildings, CSIRO, Australia.

ANZECC. 1998. Towards Sustainability - Achieving Cleaner Production in Australia [Online]. Australian and New Zealand Environment and Conservation Council. Available: http://nepc.gov.au/system/files/resources/378b7018-8f2a-8174-39282056b44bf9b0/files/anzecc-ppr-towards-sustainability-achieving-cleaner-productionaustralia-199812.pdf [Accessed 1 October 2018].

ASBEC. 2016. A national framework for residential ratings: Discussion paper [Online]. Australian Sustainable Built Environment Council. Available: http://www.asbec.asn.au/researchitems/residential-ratings/ [Accessed 27 April 2018].

ASBEC. 2018. The bottom line: The household impacts of delaying improved energy requirements in the Building Code [Online]. Australian Sustainable Built Environment Council. Available: http://www.asbec.asn.au/research-items/bottom-line-household-impacts-building-code/ [Accessed 27 April 2018].

Australian Government. 2015. Australia's 2030 climate change target [Online]. Australian Government. Available: http://www.environment.gov.au/climatechange/publications/factsheet-australias-2030-climate-change-target [Accessed 30 April 2018].

Bazeley, P. 2007. Qualitative data analysis with NVivo, SAGE, London.

Bazeley, P. 2013. Qualitative data analysis : practical strategies, SAGE, Thousand Oaks, Calif.

Berardi, U. (2012), "Sustainability Assessment in the Construction Sector: Rating Systems and Rated Buildings". Sustainable Development, Vol. 20 No. 6. pp. 411-424. 10.1002/sd.532 
Berry, S. and Marker, T. (2015a), “Australia's nationwide house energy rating scheme: the scientific basis for the next generation of tools". International Journal of Sustainable Building Technology and Urban Development, Vol. 6 No. 2. pp. 90-102.

Berry, S. and Marker, T. (2015b), "Residential energy efficiency standards in Australia: where to next?”. Energy Efficiency, Vol. 8 No. 5. pp. 963-974. 10.1007/s12053-015-9336-4

Chileshe, N.Rameezdeen, R. and Hosseini, M. R. (2016), "Drivers for adopting reverse logistics in the construction industry: a qualitative study". Engineering, Construction and Architectural Management, Vol. 23 No. 2. pp. 134-157.

ClimateWorks 2016. Low carbon, high performance: How buildings can make a major contribution to Australia's emissions and productivity goals, Australian Sustainable Built Environment Council, Sydney, Australia.

ClimateWorks. 2018. Expert report: Improve home energy standards or risk bigger bills, more emissions [Online]. Available: https://climateworks.com.au/story/media-release/expert-reportimprove-home-energy-standards-or-risk-bigger-bills-more-emissions [Accessed 27 April 2018].

Dainty, A. R. J.Bagilhole, B. M. and Neale, R. H. (2000), “A grounded theory of women's career under-achievement in large UK construction companies". Construction Management and Economics, Vol. 18 No. 2. pp. 239-250. 10.1080/014461900370861

Daniel, L.Williamson, T. and Soebarto, V. (2017), "Comfort-based performance assessment methodology for low energy residential buildings in Australia". Building and Environment, Vol. 111. pp. 169-179. https://doi.org/10.1016/j.buildenv.2016.10.023

Darko, A.Zhang, C. and Chan, A. P. C. (2017), "Drivers for green building: A review of empirical studies". Habitat International, Vol. 60. pp. 34-49. https://doi.org/10.1016/j.habitatint.2016.12.007

Dimitriadis, G. and Kamberelis, G. 2013. Focus Groups: From Structured Interviews to Collective Conversations, Taylor and Francis, Abingdon, Oxon.

Doan, D. T.Ghaffarianhosseini, A.Naismith, N.Zhang, T. and Ghaffarianhosseini, A. (2017), "A critical compariosn of green building rating systems". Building and Environment, Vol. 123. pp. 243-260.

Durlauf, S. N. and Young, H. P. 2001. Social Dynamics, Bookings Institution Press and The MIT Press, Washington D.C.

Foong, D.Mitchell, P.Wagstaff, N.Duncan, E. and McManus, P. (2017), "Transitioning to a more sustainable residential built environment in Sydney?". Geo: Geography and Environment, Vol. 4 No. 1. pp. e00033-n/a. 10.1002/geo2.33

GBCA. 2018. Green Star [Online]. Green Building Council of Australia. Available: https://new.gbca.org.au/ [Accessed 3 March 2018].

Gibbs, D. and O'Neill, K. (2017), "Future green economies and regional development: a research agenda". Regional Studies, Vol. 51 No. 1. pp. 161-173. 10.1080/00343404.2016.1255719

Gou, Z. and Xie, X. (2017), “Evolving green building: triple bottom line or regenerative design?”. Journal of Cleaner Production, Vol. 153. pp. 600-607. 
Guest, G.Namey, E. and McKenna, K. (2017), "How Many Focus Groups Are Enough? Building an Evidence Base for Nonprobability Sample Sizes". Field Methods, Vol. 29 No. 1. pp. 3-22. $10.1177 / 1525822 \times 16639015$

Hakkinen, T. and Belloni, K. (2011), "Barriers and drivers for sustainable building". Building Research \& Information, Vol. 39 No. 3. pp. 239-255.

Hall, N. 2014. The energy fit homes initiative. Low Carbo Living Forum: The centre for liveability real estate.

Hatvani-Kovacs, G.Belusko, M.Pockett, J. and Boland, J. (2018), "Heat stress-resistant building design in the Australian context". Energy and Buildings, Vol. 158. pp. 290-299. https://doi.org/10.1016/j.enbuild.2017.10.025

Iyer-Raniga, U.Moore, T. and Wasiluk, K. (2014), "Residential building sustainability rating tools in Australia". Environment Design Guide, No. 80. pp. 1-14.

Jackson, S. (2016), "A summary of urban assessment tools for application in Australia". Environment Design Guide, No. 84. pp. 1.

JLL and WSP. 2015. An Overview of the Rating Tool Landscape in Australia [Online]. Available: http://www.jll.com.au/australia/en-au/Research/AU-EnvironmentCert-v9.pdf [Accessed 2 October 2018].

Kivimaa, P.Hildén, M.Huitema, D.Jordan, A. and Newig, J. (2017), "Experiments in climate governance - A systematic review of research on energy and built environment transitions". Journal of Cleaner Production, Vol. 169. pp. 17-29. https://doi.org/10.1016/j.jclepro.2017.01.027

Lewins, A. and Silver, C. 2007. Using software in qualitative research, SAGE Publications, London, England.

Li, Y.Chen, X.Wang, X.Xu, Y. and Chen, P.-H. (2017), “A review of studies on green building assessment methods by comparative analysis". Energy and Buildings, Vol. 146. pp. 152-159.

Love, P. E. D.Niedzweicki, M.Bullen, P. A. and Edwards, D. J. (2012), "Achieving the Green Building Council of Australia's World Leadership Rating in an Office Building in Perth". Journal of Construction Engineering and Management, Vol. 138 No. 5. pp. 652-660. doi:10.1061/(ASCE)CO.1943-7862.0000461

Lu, H. R.El Hanandeh, A. and Gilbert, B. P. (2017), “A comparative life cycle study of alternative materials for Australian multi-storey apartment building frame constructions: Environmental and economic perspective". Journal of Cleaner Production, Vol. 166. pp. 458-473. https://doi.org/10.1016/j.jclepro.2017.08.065

Markard, J.Raven, R. and Truffer, B. (2012), "Sustainability transitions: An emerging field of research and its prospects". Research policy, Vol. 41 No. 6. pp. 955-967.

Martek, I.Hosseini, M. R.Shrestha, A.Zavadskas, E. K. and Seaton, S. (2018), “The sustainability narrative in contemporary architecture: Falling short of building a sustainable future". Sustainability, Vol. 10 No. 981.

Martinaitis, V.Zavadskas, E. K.Motuzienė, V. and Vilutienė, T. (2015), "Importance of occupancy information when simulating energy demand of energy efficient house: A case study". Energy and Buildings, Vol. 101. pp. 64-75. https://doi.org/10.1016/j.enbuild.2015.04.031 
Masanauskas, J. 2014. Melbourne's continuing population boom means another 720,000 homes will be needed by 2031 [Online]. Herals Sun. Available:

http://www.heraldsun.com.au/news/victoria/melbournes-continuing-population-boom-meansanother-720000-homes-will-be-needed-by-2031/newsstory/98872b3ab27f00891d50c694adba7abd [Accessed 28 February 2018].

Mcguirk, P.Dowling, R.Brennan, C. and Bulkeley, H. (2015), "Urban Carbon Governance Experiments: The Role of Australian Local Governments". Geographical Research, Vol. 53 No. 1. pp. 39-52. doi:10.1111/1745-5871.12098

Merriam, S. B. 2014. Qualitative Research : A Guide to Design and Implementation. 3rd ed. San Fransisco, CA: Jossey-Bass.

Mitchell, L. M. 2010. Green Star and NABERS: Learning from the Australian Experience with Green Building Rating Tools. In: BOSE, R. K. (ed.) Energy Efficient Cities : Assessment Tools and Benchmarking Practices. World Bank Publications, Washington DC.

Morgan, D. L. 1997. Focus Groups as Qualitative Research. Thousand Oaks, California: SAGE Publications, Inc.

Morgan, D. L. 2012. Focus Groups and Social Interaction In: GUBRIUM, J. F., HOLSTEIN, J. A., MARVASTI, A. B. \& MCKINNEY, K. D. (eds.) The SAGE Handbook of Interview Research: The Complexity of the Craft. 2 ed, SAGE Publications, Inc., Thousand Oaks, California.

NABERS. 2018. Why NABERS? [Online]. Office of Environment and Heritage. Available: https://www.nabers.gov.au/about/what-nabers/why-nabers [Accessed 1 October 2018].

Olubunmi, O. A.Xia, P. B. and Skitmore, M. (2016), "Green building incentives: A review". Renewable and Sustainable Energy Reviews, Vol. 59. pp. 1611-1621. https://doi.org/10.1016/j.rser.2016.01.028

Rashid, M.Spreckelmeyer, K. and Angrisano, N. (2012), "Green buildings: Environmental awareness and corporate image". Journal of Corporate Real Estate, Vol. 14 No. 1. pp. 21-49.

Raven, R.Schot, J. and Berkhout, F. (2012), "Space and scale in socio-technical transitions". Environmental Innovation and Societal Transitions, Vol. 4. pp. 63-78. https://doi.org/10.1016/j.eist.2012.08.001

Saman, W. Y. (2013), "Towards zero energy homes down under”. Renewable energy, Vol. 49. pp. 211-215.

Sandy, B. (2011), "Barriers and drivers to green buildings in Australia and New Zealand". Journal of Property Investment \& Finance, Vol. 29 No. 4/5. pp. 494-509. doi:10.1108/14635781111150367

Smoleniec, L.McManus, P. and Duncan, E. (2017), "Understanding the dynamics of sustainability transitions: the Home Insulation Program". Australian Geographer, Vol. 48 No. 4. pp. 497517. 10.1080/00049182.2017.1345295

Tam, V. and Zeng, S. X. (2013), "Sustainable performance indicators for Australian residential buildings". Journal of Legal Affairs and Dispute Resolution in Engineering and Construction, Vol. 5 No. 4. pp. 168-179. 
Truffer, B. and Coenen, L. (2012), "Environmental innovation and sustainability transitions in regional studies". Regional Studies, Vol. 46 No. 1. pp. 1-21.

Truffer, B.Murphy, J. T. and Raven, R. 2015. The geography of sustainability transitions: Contours of an emerging theme. Elsevier.

van der Heijden, J. 2014. Green building revolution? Only in high-end new CBD offices [Online]. The Conversation. Available: http://theconversation.com/green-building-revolution-only-in-highend-new-cbd-offices-24535 [Accessed 22 February 2018].

van der Heijden, J. (2015), "On the potential of voluntary environmental programmes for the built environment: A critical analysis of LEED". Journal of Housing and Built Environment, Vol. November.

Van der Heijden, J. (2016), “The new governance for low-carbon buildings: mapping, exploring, interrogating”. Building Research \& Information, Vol. 44 No. 5-6. pp. 575-584. 10.1080/09613218.2016.1159394

van der Heijden, J. (2018), "From leaders to majority: a frontrunner paradox in built-environment climate governance experimentation". Journal of Environmental Planning and Management. pp. 1-19. 10.1080/09640568.2017.1350147

Vieira, L. C. and Amaral, F. G. (2016), "Barriers and strategies applying Cleaner Production: a systematic review". Journal of Cleaner Production, Vol. 113. pp. 5-16. https://doi.org/10.1016/j.jclepro.2015.11.034

Warren-Myers, G.Judge, M. and Paladino, A. (2018), "Sustainability ratings in residential development: a worthwhile endeavour?". International Journal of Building Pathology and Adaptation, Vol. 36 No. 4. pp. 353-372. doi:10.1108/IJBPA-02-2018-0024

Williams, K. and Dair, C. (2007), "What is stopping sustainable building in England? Barriers experienced by stakeholders in delivering sustainable developments". Sustainable development, Vol. 15 No. 3. pp. 135-147.

Wong, S. Y.Susilawanti, C.MillerWendy and Mardiasmo, D. 2015. A comparison of international and Australian rating tools for sustainability elements of residential property. COBRA Sydney, NSW: RICS and COBRA.

Wong, S. Y.Susilawati, C.Miller, W. and Mardiasmo, D. (2018), "Improving Information Gathering and Distribution on Sustainability Features in the Australian Residential Property Market". Journal of Cleaner Production. https://doi.org/10.1016/j.jclepro.2018.02.163

Xia, B.Chen, Q.Skitmore, M.Zuo, J. and Li, M. (2015), “Comparison of sustainable community rating tools in Australia". Journal of Cleaner Production, Vol. 109. pp. 84-91. https://doi.org/10.1016/j.jclepro.2015.08.016

Xia, B.Zuo, J.Skitmore, M.Pullen, S. and Chen, Q. (2013), “Green Star points obtained by Australian building projects". Journal of Architectural Engineering, Vol. 19 No. 4. pp. 302-308.

Yang, J. and Yang, Z. (2015), "Critical factors affecting the implementation of sustainable housing in Australia". Journal of Housing and the Built Environment, Vol. 30 No. 2. pp. 275-292.

Zuo, J.Xia, B.Chen, Q.Pullen, S. and Skitmore, M. (2013), "Green building rating for office buildings: Lessons learned”. Journal of Green Building, Vol. 11 No. 2. pp. 131-146. 
Zuo, J. and Zhao, Z. Y. (2014), "Green building research - Current status and future agenda: A review". Renewable and Sustainable Energy Reviews, Vol. 30. pp. 271-281. 